\title{
A pesquisa-intervenção como método de estudo do trabalho docente
}

\author{
The Intervention Research as a Study Method of the Teaching Work
}

\author{
Alini Altoé; Cristiana Mara Bonaldi \\ Universidade Federal do Espírito Santo; Universidade Federal Fluminense
}

\section{RESUMO:}

Apresenta os caminhos percorridos para a construção de pesquisa de mestrado, que versa sobre a formação e o trabalho de professores(as), realizada no Instituto Federal do Espírito Santo, Campus São Mateus. Descreve como se estabeleceram os primeiros contatos com os(as) docentes a fim de construir um território de confiança, o que se desenvolvia em cada encontro, e traz algumas das análises produzidas pelo grupo. $\mathrm{O}$ método se delineia no encontro entre campo, participantes e pesquisadoras, no âmbito de uma pesquisaintervenção, registrada em diário de campo. Assim, outros modos de pesquisar foram tecidos com o grupo de professores(as), a partir da emersão de deslocamentos, desnaturalizações, compartilhamentos e construções no decorrer da investigação. Desse modo, destaca os pequenos grupos, a atenção aos detalhes, as conversas e experienciações como ferramentas para fissurar as tradições escolares e as formas de existência que aprisionam a vida.

Palavras-chave: pesquisa-intervenção; diário de campo; trabalho docente.

\begin{abstract}
:
This article presents the paths taken for the construction of a master degree's research, which deals with the training and work of teachers, held at the Instituto Federal do Espírito Santo, Campus São Mateus. It describes how the first contacts with teachers were established in order to build a territory of trust, which was developed in each meeting, and includes some of the analysis produced by the group. The method is outlined in the meeting between field, participants and researchers, within the scope of an intervention research, recorded in a field diary. Thus, other ways of researching were created with the group of teachers, from the arisen of displacements, denaturalizations, shares and constructions in the course of the investigation. In this way, it highlights small groups, attention to details, conversations and experiences as tools to crack school traditions and forms of existence that imprison life.
\end{abstract}

Key-words: intervention research; field diary; teaching work.

DOI: 10.12957/mnemosine.2020.57666

\section{Introdução}

Nosso interesse em pesquisar ${ }^{1}$ o trabalho docente emergiu a partir dos encontros que experienciamos nas escolas onde pudemos estudar e trabalhar como psicóloga. 
Inquietamo-nos diante dos sofrimentos de estudantes e trabalhadores(as) ${ }^{2}$, enunciados como tristeza, angústia, medo e insegurança. Outras vezes esses foram inaudíveis, mas nem por isso não foram sentidos por nossos corpos.

Definimos como o local da pesquisa o Campus São Mateus do Instituto Federal do Espírito Santo, uma escola de educação profissional e tecnológica, com práticas impregnadas pela lógica produtivista de formação para o trabalho. Ou seja, formação de profissionais, de mão de obra para o mercado de trabalho.

A qualidade e a eficiência, características tão prezadas e difundidas, mascaravam, muitas vezes, o sofrimento e a lógica produtivista do capitalismo, das capacitações que valorizavam apenas a técnica. Percebíamos que, por vezes, também se adotava uma perspectiva de educação como salvadora da sociedade, aquela que produz cidadãos(ãs) críticos(as) e conscientes, que forma sujeitos solucionadores de problemas sociais.

Nessa perspectiva, os modos de ser professor(a) também estavam atravessados pelas lógicas do treinamento, do tecnicismo, da valorização da reprodução e da aplicação de métodos e técnicas para ensinar. E também invadidos pela lógica da libertação, uma salvação que se dá pela aquisição de conhecimentos e habilidades. Esses discursos eram forças que perpassam o trabalho docente (OLIVEIRA, 2013).

E, por vezes, os(as) professores(as) acreditavam que precisavam aprender técnicas de como ensinar aos(às) estudantes. Como se houvesse um modelo de estudante e como se esses(as) aprendessem do mesmo modo. E, quando alguém não aprendia, dizia-se que ele(a) não havia se esforçado suficientemente; logo, não tinha condições, ainda, de progredir de série. Percebíamos que, diante do(a) estudante que se distanciava desse modelo, surgia o medo de não saber o que e como fazer.

Sentíamos que havia uma tendência a psicologizar a escola, os(as) estudantes e os(as) trabalhadores(as), como se os sofrimentos fossem responsabilidade de um indivíduo abstrato, apartado de suas relações sociais, econômicas, culturais etc. Algumas análises pouco consideravam os aspectos que atravessavam a escola e os processos de ensino e aprendizagem. Seguia-se pela lógica do encaminhamento e da culpabilização.

Além disso, havia outros fatores que tornavam difíceis as conversas: as urgências produzidas nas práticas cotidianas da escola, o calendário acadêmico que não previa momentos para as conversas entre os(as) trabalhadores(as) e a ausência de espaços físicos que acolhessem um número maior de pessoas. 
Diante de tais situações, nos questionávamos: será possível produzir uma outra escola? Uma escola que produza outras relações? Havia outros modos de ser professor(a)?

\title{
Metodologia
}

Nessa direção, pesquisar o trabalho docente no Ifes Campus São Mateus fazia referência à lentificação do tempo com a pretensão de valorizar as problematizações como possibilidade de criar rachaduras, furos, brechas nos modos habituais de ser professor(a). Uma tentativa de romper com modos que regulamentavam a vida. Tratava-se de uma aposta em modos de trabalho que atentassem para as subjetividades ${ }^{3}$ produzidas nessa escola, sem dicotomizar o trabalho e a formação, a escola e a vida.

Propúnhamos uma análise micropolítica da escola.

\begin{abstract}
A questão micropolítica - ou seja, a questão de uma analítica das formações do desejo no campo social - diz respeito ao modo como o nível das diferenças sociais mais amplas (que chamei de 'molar') se cruza com aquele que chamei de 'molecular'. Entre esses dois níveis, não há uma oposição distintiva, que dependa de um princípio lógico de contradição. Parece difícil, mas é preciso simplesmente mudar de lógica. Na física quântica, por exemplo, foi necessário que um dia os físicos admitissem que a matéria é corpuscular e ondulatória, ao mesmo tempo. Da mesma forma, as lutas sociais são, ao mesmo tempo, molares e moleculares (GUATTARI; ROLNIK, 2013: 149, grifo dos autores).
\end{abstract}

O nível molar se refere ao plano das formas, àquilo que está instituído ${ }^{4}-$ como as leis, normas e tradições da escola, tais como: o currículo, a normativa de recuperação, os códigos de ética, as avaliações, as teorias da aprendizagem. Por outro lado, o molecular se relaciona ao plano das forças, das intensidades e dos embates que vão modificando a realidade: são as forças instituintes ${ }^{5}$.

Vale destacar que não há, entre molar e molecular, uma contradição, mas entrecruzamentos e prolongamentos. Molar e molecular coexistem e não estão em uma relação antagônica. A grande questão micropolítica é como criamos dispositivos para produzir fissuras e bifurcações nas problemáticas, como colocamos e recolocamos as questões (GUATTARI; ROLNIK, 2013).

Por isso, nesta pesquisa, procurávamos atentar aos modos tradicionais de trabalho docente, aqueles aliados à regulamentação da vida, mas também aos modos que furavam os controles, que escapavam, que possibilitavam experienciar outros modos de ser 
professor(a). Uma análise que comportasse a multiplicidade: não vislumbrávamos isso ou aquilo, mas isso e aquilo (HECKERT; ROCHA, 2012).

Inquietávamo-nos ao pensar como os modos de ser professor(a) foram constituídos, que modos de subjetivação estavam em curso naquela escola e quais efeitos produziam. Tratava-se de uma análise que tentava contemplar a multiplicidade de atravessamentos entre forças e formas, entre os níveis molar e molecular, rompendo com a ideia de um sujeito abstrato, suspenso de suas relações (GUATTARI; ROLNIK, 2013). Existia atenção às minúcias do trabalho docente, às problematizações e inquietações, àquilo que muitas vezes não notávamos ou a que não concedíamos a devida importância.

Em uma escola onde o treinamento, o tecnicismo, a reprodução, a aplicação de métodos, a solução de problemas técnicos e sociais são prerrogativas - para alguns sujeitos - de uma educação de qualidade, não era fácil problematizar, pois esse exercício de pensamento estremecia as certezas e as verdades que ali imperavam.

A fim de construir uma análise micropolítica da escola, adotamos a pesquisaintervenção como metodologia. Essa escolha justifica-se pelo fato de a pesquisaintervenção problematizar os saberes e as práticas instituídos, questionar os conhecimentos cristalizados e possibilitar a construção de novas práticas na educação (ROCHA, AGUIAR, 2003).

Nessa perspectiva, a um só tempo, há produção de conhecimento e transformação da realidade. O conhecer não é desencarnado ou uma abstração sobre uma realidade, “[...] não é tão somente representar o objeto ou processar informações acerca de um mundo supostamente já constituído, mas pressupõe implicar-se com o mundo, comprometer-se com a sua produção. Nesse sentido, o conhecimento ou, mais especificamente, o trabalho da pesquisa se faz pelo engajamento daquele que conhece no mundo a ser conhecido [...]" (ALVAREZ; PASSOS, 2015: 131).

Assim, nossa investigação foi construída com os(as) professores(as) e não para investigar o trabalho dos(as) professores(as); almejávamos produzir análises com eles(as) e não sobre eles(as). Para tal foi preciso nos colocarmos lado a lado com os(as) professores(as), intenção esta comunicada aos(às) integrantes da pesquisa, como descrito no excerto de diário de campo, a seguir:

Em algum momento Danilo ${ }^{6}$ nos perguntou se iríamos observar o trabalho deles(as). Fomos explicando que não estaremos na escola para observar ou julgar o trabalho dos(as) professores(as), mas que produziremos análises de forma coletiva no grupo, no sentido do que tem funcionado ou não e que a partir disso vamos construindo e 
experienciando outros modos. Que precisamos ir sentindo (que não fala só de sentimento racional, mas de algo que se dá em nossos corpos que não conseguimos explicar exatamente com palavras) quais são os efeitos dos nossos modos de ensinar, de trabalhar e de ser professor(a) (FRAGMENTO DO DIÁRIO DE CAMPO).

O saber sobre algo ou alguém busca controlar o objeto de estudo, explicá-lo, confirmar ou refutar hipóteses, tem como pressuposto a neutralidade. O "saber com" fala de uma pesquisa encarnada, “[...] a prática da investigação não pode ser determinada só pelo interesse do pesquisador, devendo considerar também o protagonismo do objeto. A investigação é cuidado ou cultivo de um território existencial no qual o pesquisador e o pesquisado se encontram" (ALVAREZ; PASSOS, 2015: 144).

Pesquisadores(as) e participantes se constituem no mesmo plano, coemergem na relação, não havendo pesquisadores(as) ou participantes pré-definidos(as). Ambos se constroem e se modulam nos encontros que experienciam (ALVAREZ; PASSOS: 2015).

Portanto, nossa intenção não foi aplicar um método para verificar uma hipótese ou isolar variáveis e as controlar a fim de neutralizar a relação sujeito e objeto (pesquisadoras e participantes). Reconhecíamos que havia produção de interferência e ela era condição ao próprio conhecimento (STENGERS, 1990). Não pretendíamos generalizar um conhecimento verificável e neutro.

\section{Desenvolvimento}

Com a finalidade de construir outros modos de pesquisar, que rompessem com os tradicionais, fomos estabelecendo conversas com os(as) professores(as) do Ifes Campus São Mateus, falando de nossas intenções de pesquisa: construir um grupo com os(as) professores(as) para conversar a respeito do trabalho docente e produzir análises coletivas. Essas primeiras abordagens aos(às) professores(as) ocorreram em situações e locais não estruturados, como nos intervalos de aulas, nos corredores da escola, na cantina, nos banheiros, entre outros.

Buscávamos construir um território de confiança, no qual os(as) participantes pudessem se perceber como corresponsáveis e protagonistas na pesquisa; afinal, eles(as) produziriam análises e construiriam outros modos de ser professor(a).

Posteriormente, encaminhamos um e-mail para todos(as) os(as) professores(as) da escola, apresentando os objetivos da pesquisa e os(as) convidando para uma reunião 
inicial, na qual conversaríamos sobre os detalhes da proposta.

Alguns(mas) docentes iniciaram as conversas via e-mail. Surgiram curiosidades, dúvidas e a proposição de outros horários e dias para a conversa inicial, uma vez que nem todos(as) que apresentaram interesse tinham disponibilidade na data e horário proposto.

Definimos data e horário que contemplassem a maioria dos(as) interessados(as) e agendamos a reunião. Essa conversa ocorreu no laboratório de informática da escola em que esses(as) professores(as) atuavam. Iniciamos perguntando o que os(as) fez querer participar dessa pesquisa, almejando assim compreender o que os(as) inquietava e quais eram os desafios do trabalho docente que naquele momento emergiam como questão para eles(as). Estavam na reunião dois professores e uma professora.

Quarta-feira às 9 h iniciamos nossa conversa no Ifes Campus São Mateus sobre o projeto de pesquisa "Subjetivação e formação de professores". Chegamos à escola animadas com a conversa, não que esperássemos uma sala lotada, mas porque falar sobre o tema, os motivos da pesquisa, como estávamos pensando era algo que nos alegrava.

Na segunda-feira o diretor de ensino disparou um e-mail para os(as) professores(as) convidando-os(as) para essa conversa de hoje, no qual explicávamos brevemente o teor da proposta. Com alguns(mas) professores(as) iniciamos uma conversa no próprio email, uma vez que ele foi encaminhado com cópia para nós.

Já achamos bastante interessante esse retorno. Alguns(mas) disseram que acharam a proposta bacana, mas que no horário combinado não poderiam comparecer. Marcamos outro horário para a conversa. Acreditávamos que o momento de conversar sobre a proposta era bastante importante, no sentido de valorizar o interesse dos(as) professores(as) e pensar como aquela pesquisa os(as) afetou.

Então iniciamos a conversa assim: como a proposta encaminhada por e-mail os(as) afetou? O que vocês esperam da pesquisa? O que prevaleceu nas falas foi pensar "em outras formas de chegar ao aluno" e "construir práticas diferentes".

Paula $^{7}$, Danilo, Bernardo e nós estávamos bastante afinados(as), parecíamos nos entender. Cada um(a) colocando as coisas a sua maneira. Havia ali uma direção ética do modo de trabalho que em muitos aspectos se aproximavam, uma direção de pensar outras estratégias de ensino, outros modos de ser professor(a), modos que rompessem com a transmissão de informação e aquisição de habilidades. Questionávamos: quais modos de ensinar, de trabalhar e de ser professor(a) potencializam ou não a vida? (GUATTARI; ROLNIK, 2013).

[...]

Conversamos por cerca de 1 hora, uma conversa franca e tranquila. Os(As) professores(as) foram trazendo suas inquietações e fomos pensando como poderíamos conversar sobre elas no grupo da pesquisa [composto pelos(as) docentes do Campus São Mateus e a pesquisadora]. Também fomos puxando os fios para falar da pesquisaintervenção (metodologia de pesquisa que utilizaremos), aquela que produz transformações à medida que intervém na realidade, na qual não separamos teoria e prática" (FRAGMENTO DO DIÁRIO DE CAMPO).

No período vespertino, conversamos com mais três professores e uma professora, que estavam em aula no período matutino e, por isso, não puderam participar da reunião. 
Também apresentamos a proposta da pesquisa e acolhemos suas dúvidas, sugestões e expectativas, como podemos acompanhar na conversa com Saulo?:

[...] professor da coordenadoria de Mecânica, que não pôde participar da conversa [apresentação da proposta de pesquisa] pela manhã, pois estava em aula. Então, conversamos à tarde, conforme combinado. Acomodamo-nos na cantina, pois não havia sala disponível. A primeira pergunta que ele nos fez foi: "como você coletará os dados?".

Falamos do diário de campo, ferramenta que será utilizada na pesquisa para registrar o que acontecer no grupo, não como uma descrição, mas para acolher os pontos que chamarem nossa atenção, que nos afetarem, que nos fizerem questões e que interpelarem o grupo.

Os(As) professores(as) também utilizarão a escrita para problematizarem seus modos de trabalho, questionarem-se, construírem outros modos de ensinar e, também, para pensarem o próprio percurso da pesquisa. Experienciaremos prosas, poesias, contos, obras de arte, escreveremos e outras coisas que surgirem. Conforme o grupo for fazendo seu percurso, lançaremos mão de algumas ferramentas que possam gerar abalos em nossos modos habituais de trabalho.

Fomos conversando, e o professor nos contou que tem vivido muitas inquietações sobre seu modo de trabalhar. Dúvidas sobre como ensinar, se está fazendo um bom trabalho como professor e se está fazendo seu melhor. Disse que já chegou a pensar em solicitar exoneração do cargo de professor e procurar outra atividade.

Sua fala parecia cheia de medo e insegurança frente ao trabalho docente. Até que ele enunciou a preocupação em analisar seu trabalho em um grupo. Ele percebe que nessa escola quando você solicita ajuda, quando problematiza seu modo de ensinar, alguns(mas) colegas acham que "você é lixo", e que há na escola o grupo dos "the best professores" que se portam como se tudo soubessem" (FRAGMENTO DO DIÁRIO DE CAMPO).

Assim, construir um território de confiança não foi um processo que se produziu com boa vontade e nem apenas com o apelo "confiem!". A confiança precisou ser cultivada, indo ao encontro do conceito exposto por Sade et alii. (2013: 238): “[...] confiança - con fiar - fiar com, tecer com, composição e criação com o outro/outrem". Os(As) professores(as) precisaram sentir que participariam efetivamente das construções da pesquisa, que suas singularidades seriam levadas em conta. Não se tratava de um apagamento ou apaziguamento das diferenças, mas de como compor com elas.

\section{Os encontros}

A partir do interesse e da disponibilidade dos(as) professores(as), compusemos o grupo da pesquisa. Éramos três professores, quatro professoras e a pesquisadora (que também é psicóloga nessa escola e que, no período da pesquisa, se encontrava em licençacapacitação para cursar o mestrado). 
Decidimos qual o melhor dia e horário para os encontros em conjunto, às terçasfeiras no período das $14 \mathrm{~h} 30$ às $16 \mathrm{~h} 30$. Os encontros eram quinzenais e ocorriam numa sala de aula da própria escola. Ao longo do ano letivo foi preciso adaptar o tempo dos encontros para 1 hora e 30 minutos, devido aos horários de aula dos(as) participantes. Realizamos oito encontros com os(as) professores(as), e a participação variava, pois nem todos(as) os(as) participantes estiveram presentes nesses oito encontros.

O planejamento das atividades era construído conforme as questões que emergiam no próprio grupo. Então, retraçávamos as rotas, percorríamos caminhos que desconhecíamos ou que não imaginávamos que seriam visitados. Éramos guiados(as) pelo grupo e não apenas pelo interesse das pesquisadoras.

Em nosso primeiro encontro, conversamos sobre o que era educação e aprendizagem para aqueles(as) professores(as). Também apresentamos os principais conceitos discutidos no artigo "Aprendizagem, arte e invenção" (KASTRUP, 2001) e fomos articulando-os com nossa conversa. Por fim, entregamos uma cópia do artigo mencionado para que pudessem fazer a leitura posteriormente.

No segundo encontro, retomamos os principais pontos do encontro anterior e alguns(mas) professores(as) trouxeram destaques do artigo "Aprendizagem, arte e invenção" (KASTRUP, 2001). Fizemos a leitura de duas crônicas: "Carência do poder criador" (LISPECTOR, 1984a) e "Sensibilidade inteligente" (LISPECTOR, 1984b), e conversamos sobre como estimular a inteligência sensível no cotidiano da escola e nas práticas docentes.

Durante o terceiro encontro, realizamos a leitura do poema "Poesia por acaso" (PACHECO, 2017) e fizemos uma experienciação com a escrita, solicitando que cada participante escrevesse um poema. A escrita foi livre, cada um(a) podia escrever aquilo que o (a) estava atravessando, sem fazer julgamentos (certo ou errado). A escrita de cada um(a) apresentava o que estavam sentindo necessidade de escrever. Esses(as) foram convidados(as) a ler suas produções, caso se sentissem à vontade. Conversamos sobre como foi escrever uma poesia a partir da leitura do poema de Pacheco (2017) e também acerca de como a escrita pode contribuir no processo de problematização dos modos de trabalho e vida.

Solicitamos que fizessem a leitura da "Carta ao Zézim" (ABREU, 2015) e escrevessem suas próprias cartas contando como era ser professor(a), quais eram seus 
desafios, como faziam para lidar com eles e o que os (as) inquietava em sua prática docente. Iniciamos o compartilhamento das cartas escritas pelos(as) professores(as) no quarto encontro, e conversamos sobre as questões trazidas por eles(as) e sobre a experiência de escrever.

A seguir, apresentamos fragmentos da carta produzida pelo professor Danilo:

Prezados colegas,

O meu ano começou com uma dúvida. O que significa essa sigla STEM? Eu havia sido selecionado para fazer um curso na Universidade de São Paulo, ficaria lá uma semana, estudando alguma coisa que tinha a ver com meus objetivos profissionais de especializar-me cada vez mais no ensino de ciências e o foco dos estudos era esse tal STEM. Acho que até os organizadores do curso, por parte da USP, não tinham certeza o que era STEM. Logo o pessoal do LSI-Tec, que é superorganizado e envolvido com essas coisas...

[...]

Mas os cinco dias de curso não foram suficientes para explicar o que era STEM. O curso tinha muita informação. Trouxeram profissionais de grandes empresas espalhadas pelo mundo para conversar conosco. Isso mesmo, era uma conversa. Curso diferente. Tudo era estruturado em tarefas voltadas ao planejamento do ensino de ciências da realidade de trabalho de cada um de nós com a intervenção, muitas vezes um bate-papo, desse pessoal que vinha de toda parte do mundo. Como aprender alguma coisa assim? Por que não estávamos ouvindo eles falarem para, então, tentarmos reproduzir?

No primeiro dia descobri que STEM é a sigla utilizada para Science, Technology, Engineer e Math. Mas isso não ajudou nada. Talvez tenha piorado quando os americanos explicaram que lá eles usam o SteAm: Science, Technology, Engineer, Arts e Math. Mas o que era isso? Mais uma sigla para um projeto mirabolante, tipo aqueles dos quais li, que os EUA tentaram introduzir (ou o governo brasileiro, sei lá...) de lá para cá décadas atrás para educação?

$[\ldots]$

Aos poucos fui percebendo que a estrutura do curso era algo incrível, do tipo que eu nunca tinha pensado. As coisas foram se encaixando, mas não logo, demorou alguns dias depois do curso para que eu compreendesse o que havia sido tudo aquilo. Nos Estados Unidos parte do currículo escolar se chama STEAM. É a forma com que eles têm procurado ensinar não só ciências. Eles procuram fazer tudo conectado, a tecnologia como produto científico (e vice-versa) indissociável do pensar matemático, com possibilidades de prototipagem (engenharia). Além disso, eles pensam tudo conectado à Arte, ou seja, a percepção cultural de cada um para a construção pelo pensar lógico. Esta última parte eles acharam difícil trazer para o Brasil, pois as questões artísticas, quando acessíveis à população, raramente estão conectadas ao STEM. Quando comecei a entender isto, percebi que a grande pergunta deles era: como você vai fazer STEM na sua prática como profissional da educação?

Essa pergunta veio de forma muito bacana. Porque era muito claro que eles não tinham intenção de incutir um currículo na nossa prática, mas de mostrar possibilidades para que fôssemos instrumentos de transformação do espaço escolar, criando ambientes nos quais os alunos do ensino básico tenham oportunidade de realmente manipular as letrinhas da sigla STEM.

Mas o que criar e como criar? O curso me ajudou muito a pensar sobre a promoção de feiras de ciências, algo que faço há nove anos [...]". 
Danilo discorreu sobre as alegrias, as dificuldades e as inquietações produzidas pelo curso que realizou na Universidade de São Paulo e sobre como estranhou o curso como conversa, pois estava habituado com a transmissão de informação. Também nos mostrou como essa experienciação ainda reverberava em seu corpo.

Solicitamos, para o encontro seguinte, que escrevessem um diário falando de algo que lhes acontecesse durante os quinze dias seguintes.

No quinto encontro, compartilhamos os diários, conversamos sobre os pontos que trouxeram e sobre como foi escrever. Continuamos também diálogos disparados nos encontros anteriores, que visavam ao acompanhamento das atividades realizadas pela professora Marcela ${ }^{10}$ e pelo professor Saulo. Destacamos que eles(as) poderiam registrar o desenvolvimento dessas atividades em diários, no intuito de produzir problematizações e compartilhar com o grupo.

Seguimos com o acompanhamento das atividades de Marcela e Saulo, no decorrer do sexto encontro, problematizando as práticas docentes e construindo estratégias de ensino e aprendizagem com o grupo. Para o encontro seguinte, solicitamos a escrita de um diário falando de alguma atividade que estivessem desenvolvendo com uma de suas turmas ou que criariam a partir da discussão daquele dia. Também sugerimos a leitura do texto "Formação docente: uma experimentação que produz ecos" (SELLI, 2010), nele destacando alguns pontos que seriam propícios a discussões.

Durante o sétimo encontro, compartilhamos os diários e conversamos sobre as questões que trouxeram, sobre as atividades que estavam desenvolvendo e sobre como foi escrever. Articulamos o diálogo com o artigo de Selli (2010), que trazia a experiência de uma atividade inventiva ${ }^{11}$ desenvolvida em uma escola no Rio Grande do Sul. Solicitamos, para o último encontro, que cada participante escrevesse algo sobre como foi participar do grupo com os(as) professores(as), o que os(as) afetou e como foi experienciar a escrita enquanto problematização de seu trabalho.

No encontro de encerramento, compartilhamos as nossas escritas e avaliamos o processo por meio dos seguintes questionamentos: Como foi participar dos encontros? O que eles produziram em vocês? Há sugestões? O que vocês gostariam de continuar discutindo?

Portanto, durante nossos encontros realizamos leituras de artigos, conversas; escrevemos poemas, cartas e diários de campo; compartilhamos experienciações de 
atividades desenvolvidas por esses(as) professores(as) que ofertaram visibilidade às inquietações e problematizações cotidianas dos(as) docentes; e construímos com eles(as) outras estratégias de ensino e aprendizagem, para além das habituais. Ao mesmo tempo, analisamos o que funcionava e o que não funcionava, assim como os efeitos disso no cotidiano escolar.

Construímos com os(as) professores(as) uma relação na qual seus modos de trabalho não ficaram sob suspeita ou julgamento. E isso foi acontecendo à medida que compúnhamos modos de ensinar e aprender de forma coletiva.

Afirmar que a pesquisa se assenta na confiança na experiência significa que há confiança na potência dos encontros que se dão com o (e no) campo, no processo de pesquisa. Confiar na potência de um encontro não se confunde com a ideia de completude, identidade ou convergência de interesses e finalidades. Não se trata de confiar em um resultado específico. As alianças fundadas na confiança não se sustentam na identidade de um estado de coisas ou de representações de um futuro, mas em zonas de indeterminação que nos lançam em trajetórias inventivas (SADE et alii, 2013: 284).

A confiança foi questão para Saulo desde nossa primeira conversa na cantina, quando apresentamos a pesquisa ao professor. Acreditamos que apostar nas análises com os(as) professores(as) foi condição para que as problematizações e transformações surgissem. Um território de experienciação foi tecido durante a pesquisa e, em nosso último encontro, Saulo retomou esse assunto. Marcela e Gabriela ${ }^{12}$ também apresentaram suas análises:

[...] Como falar? Se expor num grupo que conversa do trabalho docente? E então, contamos um pouco de nossa primeira conversa e de como foi importante que ela tivesse ocorrido na cantina tomando um refrigerante, onde pudéssemos falar detalhadamente da aposta dessa pesquisa. E do professor ter trazido seus medos e inquietações.

Saulo nos confirmou que essa conversa inicial foi muito importante para sua decisão de participar do grupo. 'E aos poucos fui percebendo que aqui havia cuidado de um com o outro e que eu poderia colocar minhas inquietações, dúvidas, medos e problematizações'.

Marcela destacou: 'é difícil na educação ter um espaço onde o(a) professor(a) não se sinta armado(a)'. Ficar armado se referia a assumir uma postura defensiva, como se sempre estivesse aguardando ser atacado(a) por alguém. 'Aqui eu fiquei à vontade. Não tinha medo de me expor'. Essa fala foi muito preciosa, pois ela remeteu a uma condição de enunciação criada pelo grupo. Foi muito importante construir um território de confiança. E todos(as) os(as) participantes falaram disso nesse último encontro.

Gabriela disse: 'esse território foi construído porque a mediadora se implicou no processo e não ficou numa posição de julgar os outros. Não estava ali só observando'. [...]

Gabriela acrescentou: 'não é refletir sobre o saber do outro, mas refletir com o outro as nossas práticas. Isso fez muita diferença, pois não se tratou de individualizar as 
questões ou pessoalizá-las. Mas de fazer análises coletivas das práticas' (FRAGMENTO DO DIÁRIO DE CAMPO).

Apontamos como pistas para a construção do território de confiança a conversa sobre os modos de pesquisar que sustentaríamos, a pesquisa-intervenção, na qual as questões seriam colocadas pelas pesquisadoras e pelos(as) participantes e as soluções não surgiriam de imediato e nem a partir de uma só pessoa. Muitas mãos as construiriam, sem pressa. As soluções não seriam o principal objetivo. As problematizações e os tremores provocados nos modos habituais de pensar seriam mais caros a nós.

Aos poucos, os(as) professores(as) foram trazendo as questões que os(as) inquietavam e que os(as) desafiavam em seu cotidiano de trabalho. Situações que os(as) deixava sem saber por qual caminho seguir, tais como: os(as) estudantes que supostamente não aprendiam ou aqueles(as) que não se interessavam pelo que os(as) professores(as) ensinavam ou que cumpriam as atividades apenas para obter notas.

Produzimos no grupo conversas que problematizaram os modos de trabalho docente, questões e análises que desnaturalizaram algumas formas de ensinar e aprender. Acompanhamos, ao longo dos encontros, algumas experienciações desses(as) professores(as). Falávamos dos detalhes do trabalho docente, de como desenvolviam um determinado conteúdo com os(as) estudantes. Nessas conversas emergiram novas ideias e outros modos de fazer. Não se tratava apenas de outros modos de fazer, mas de experienciar outros modos de pensar, criar, agir e sentir.

Destacamos algumas questões que surgiram no grupo: Como abrir buracos no tecnicismo que se entranha nos modos de ensinar nessa escola? Como construir modos de trabalho que fujam à lógica da produtividade e competição? Como construir outros modos de ser professor(a)? Como ensinar? Como romper com a transmissão de informações ao desenvolver um conteúdo em sala de aula? Como o(a) professor(a) sai do centro do processo de ensino e aprendizagem, do lugar daquele que ensina algo para alguém?

\section{Os diários de campo}


Lourau (1989) aponta os diários de campo como ferramentas para registro dos movimentos da pesquisa, não como uma pura descrição, mas para anotação das problematizações e inquietações dos(as) pesquisadores(as).

Nesta pesquisa, pesquisadoras e professores(as) escreveram diários de campo. Neles narraram como as situações os(as) atravessaram, selecionaram e destacaram trechos dos textos lidos, questionaram-se sobre os percursos da pesquisa e relataram como desenvolviam as atividades escolares com suas turmas.

Nos diários cabiam muitas coisas. Havia informações objetivas, como também impressões. Não se tratava de uma descrição dos fatos, dar opiniões ou fazer interpretações objetivas, mas de mostrar como as coisas aconteciam, acompanhar os processos de constituição dos modos de trabalho docente.

Os diários não tinham a intenção de contar histórias pessoais. Eles abriam possibilidades para as problematizações, para pensar o trabalho docente e a pesquisa. Tratava-se de anotações, nas quais os(as) professores(as) e as pesquisadoras puderam narrar suas experienciações de trabalho, questionar, pensar e problematizar seus modos de atuação. Colocaram em análise as forças e formas que se entrelaçavam para constituir esses modos de ser professores(as) e pesquisadoras.

Não tratamos os modos de trabalho de um(a) professor(a) como sendo dele(a), unicamente, como se as práticas representassem a boa vontade daquele(a) trabalhador(a), o que remeteria à ideia de um eu unificado, um sujeito suspenso do mundo. Mas buscamos compreender como esses modos se construíram e como poderíamos transformá-los.

Para Santos e Dias (2016: 319),

[esse tipo de registro distancia-se] da ideia de um diário confessional, 'intimo', relativo a uma individualidade como lugar onde segredos são guardados, escondidos, no qual as verdades podem libertar-se, como um campo arejado no qual seu autor precisa circular em busca de ar e seu verdadeiro eu pode aparecer em essência [...] subverte essa ideia de produção de verdade de identidades elou um texto descritivo, uma prestação de contas, veiculação de informaçães. Subversão como rompimento de hierarquias [...] (SANTOS; DIAS, 2016: 319).

Assim, a escrita diarística possibilitou a análise de como a subjetividade é atravessada por relações sociais, econômicas, culturais, de mídia, entre outras (GUATTARI; ROLNIK, 2013); e favoreceu também, nos dizeres de Oliveira (2013: 123), a criação de "[...] outros modos de ser, de experimentação de si e do outro via a escrita. 
Escrever, pois, como propósito de experimentar uma outra forma de se constituir docente", e, no âmbito deste trabalho, outra forma de se constituir pesquisadoras.

Nessa perspectiva, a escrita do diário foi uma prática de cuidado de si, “[...] um exercício de si sobre si mesmo através do qual se procura se elaborar, se transformar e atingir um certo modo de ser" (FOUCAULT, 2006: 265). Tal exercício possibilitou que cada um lançasse o olhar sobre si, criou-se tempo e espaço para ocupar-se de si. E, nesse sentido, cuidar de si é uma forma de cuidar da relação com o outro.

Logo, essa não é considerada uma prática egoísta e intimista, pois para o autor o cuidado de si envolve "[...] o conhecimento de si - este é o lado socrático-platónico -, mas é também o conhecimento de um certo número de regras de conduta ou de princípios que são simultaneamente verdades e prescrições. Cuidar de si é se munir dessas verdades [...]” (FOUCAULT, 2006: 269). Esse cuidado de si não visa à dominação e nem à competição com o outro.

A escrita dos diários possibilitava-nos questionar as verdades instituídas e produzir brechas e furos nas regras, nas normativas e nos modos de ensinar e aprender, na tentativa de construir práticas mais libertárias de educação. Assim, produzíamos outros modos de subjetivação ao escrever nossos diários de campo.

O diário pôde funcionar como dispositivo para a criação de certos modos de trabalho docente, de pesquisa e de vida. Esses modos possuíam uma direção ética de ampliar a potência da vida, ao fissurar os modelos aliados ao capitalismo que produzem sujeitos serializados.

As escritas dos diários, dos poemas, das cartas, assim como nossas conversas, funcionaram como possibilidade de reposicionamento subjetivo. Pudemos acompanhar como Marcela se lançou aos imprevistos, problematizou e experienciou outros modos de dar aula.

Marcela não escreveu seu diário. Mas nos contou cheia de alegria: 'propus um trabalho para o $4^{o}$ ano do ensino médio integrado ${ }^{13}$ e estou bem segura. Não fiquei preocupada em definir os caminhos que os(as) estudantes deveriam seguir e em estabelecer os critérios avaliativos de forma rígida, como eu sempre fazia'. Destacou que, para ela, isso é muito precioso, que, a cada detalhe que percebe que mudou, fica muito feliz.

Ressaltou que nesse grupo nós apostamos nos detalhes, na atenção às pequenas coisas, àquilo que, às vezes, passa despercebido. Contou que será um trabalho sobre história da Matemática e as mulheres.

Ficamos bastantes alegres pela forma como a professora nos trouxe essa novidade. Conseguíamos ver como essa atividade estava sendo importante para ela. Sabíamos também que esse tema a inquietava. Falar das mulheres e do machismo que atravessa 
nossas práticas. E logo ela, que sempre ficava desconfiada de seus próprios métodos, contou-nos isso toda confiante.

Ao encerrar o encontro do grupo, fomos juntas para casa, Marcela e pesquisadora, $e$ ela foi nos contando, com mais detalhes, que eles(as) farão uma exposição que comporá o evento 'Combate à violência contra as mulheres'. Cada grupo ficou com uma parte: 1) pesquisar e divulgar as mulheres matemáticas e suas descobertas; 2) indicar, na atualidade, quem são as mulheres matemáticas mais expressivas e o que elas têm estudado; 3) identificar as mulheres pesquisadoras da escola (mestrado e doutorado) $e$ o que estudaram; 4) levantar os dados das olimpíadas de matemática e fazer uma comparação do desempenho das meninas ao longo da escolarização (há uma hipótese da professora de que as meninas nos anos iniciais gostam de matemática e têm bom desempenho e que, ao longo dos anos, são desestimuladas a continuar nessa área).

Contou, ainda, que a ideia da exposição surgiu após conversar com um outro professor sobre o evento. Isso também é valioso, pois Marcela não era uma professora que habitualmente falava para seus(suas) colegas sobre seus projetos. E ela não só contou sobre o projeto, como se propôs a participar de uma atividade que exporá a produção da turma.

Ficamos pensando o quanto o evento tratar das mulheres também não foi um gatilho para a professora se lançar nessa atividade, pois, como mulheres, também sabíamos o quanto o machismo atravessa as práticas nessa escola. E ser professora de Matemática em uma escola de educação profissional e tecnológica, na qual hegemonicamente o masculino é o valorizado, não é nada trivial. O quanto dessa rigidez nos critérios e nos modos de fazer de Marcela não foram maneiras que ela encontrou para responder às convocações machistas que atravessam essa escola?

[...] esses efeitos que vimos em Marcela não foram pouca coisa [...] (FRAGMENTO DO DIÁRIO DE CAMPO).

Marcela foi nos mostrando que outros modos de ser professora eram possíveis, que outros modos de pensar, criar, agir e sentir podiam emergir. Mostrou-nos um reposicionamento subjetivo. Inicialmente, a professora se mostrava fragilizada, pouco confiante, em geral desvalorizava sua prática, e, nesse encontro, conseguimos sentir sua alegria e transformação.

Em geral, nossos encontros foram guiados pelas escritas diarísticas, ou seja, pelo que nos passava, nos tocava, nos afetava - professores(as) e pesquisadoras. Nos diários das pesquisadoras cabiam "[...] associações que ocorrem ao pesquisador durante a observação ou no momento em que o relato está sendo elaborado [...]” (BARROS; KASTRUP, 2015: 70). Portanto,

[...] a escrita do relato não deve ser um mero registro de informações que se julga importante. Longe de ser um momento burocrático, sua elaboração requer até mesmo um certo recolhimento, cujo objetivo é possibilitar um retorno à experiência do campo, para que se possa então falar de dentro da experiência e não de fora, ou seja, sobre a experiência [...] (BARROS; KASTRUP, 2015: 70-71). 
O diário de campo nos retirou da segurança dos laboratórios de pesquisa, ambientes controlados, onde há um resultado prévio a ser alcançado, e nos lançou ao imprevisto. Foi preciso cultivar uma atenção à espreita, procurando algo que não sabíamos de antemão o que era. "A ativação de uma atenção à espreita - flutuante, concentrada e aberta [...]. Ativar esse tipo de atenção significa desativar ou inibir a atenção seletiva, que habitualmente domina nosso funcionamento cognitivo [...]" (KASTRUP, 2015: 48).

Atentando-nos aos afectos e perceptos ${ }^{14}$ que foram produzidos ao habitar a escola, ao que fazia os corpos vibrarem, foi possível valorizarmos o que emergia em nossas conversas e nos diários. Aquilo que nos retirava de nossas certezas e verdades. O que abalava os automatismos do pensamento e os modos habituais de ensinar e aprender.

No livro El diario de investigación: materiales para una teoría de la implicación, Lourau (1989) apresentou diários de diferentes pesquisadores(as) e realizou análises dos textos diarísticos, destacando que esses materiais podem ter grande potencial para revelar o que atravessa o(a) pesquisador(a), pois ao falar do que ocorreu no campo de pesquisa e mostrar como a pesquisa se fez, sem deixar seus percalços de fora, o texto diarístico fala de sua própria construção (LOURAU, 1989), o que ilustramos no excerto do diário de nossa pesquisa, a seguir:

Hoje quando estávamos a caminho da escola enviamos uma mensagem em nosso grupo de WhatsApp ${ }^{15}$ lembrando o encontro. Logo Saulo disse: 'acho que não poderei participar'. Marcela, que já tinha dito que não poderia estar presente, reafirmou: 'não estarei no grupo'. Bernardo confirmou presença. Danilo disse: 'não posso, pois, a partir dessa semana, vou dar aulas à noite e acabei não conseguindo programar minha permanência à tarde no Ifes'. Gabriela informou: 'tenho outra reunião (organização de um evento) no horário do grupo'. E Paula também tinha uma reunião com um colega professor.

[...]

Parecia que precisávamos conversar com os(as) professores(as) sobre isso. Nossas implicações com esse grupo e com a pesquisa. [...] Estávamos num movimento de engajamento com o grupo, os(as) professores(as) participavam, falavam, colocavam suas dúvidas e sugestões, realizavam as atividades propostas. Mas não gostamos dessa postura de hoje, não informaram antecipadamente que não possuíam disponibilidade para o encontro, exceto Marcela.

Eles(as) sabiam que nos deslocávamos de Vitória para São Mateus, percorríamos cerca de 220 quilometros, a fim de realizar a atividade com eles(as). Não tínhamos a intenção de culpá-los(las), mas de pensar sobre nossas implicações com essa pesquisa. Como nos vinculamos a ela? Como avaliamos os encontros? Havia outras propostas para o desenvolvimento das atividades?

[...]

Então, para o próximo encontro acreditávamos que poderíamos iniciar a conversa com a análise de nossas implicações. Para disparar a conversa, exporíamos nossas 
impressões sobre a ausência dos(as) participantes ao encontro do grupo (FRAGMENTO DO DIÁRIO DE CAMPO).

Análise das implicações é um conceito, criado por Lourau (2004a), que nos ajuda a pensar como somos afetados e atravessados pelas coisas cotidianas, como nos constituímos. Nela não se defende a neutralidade do(a) pesquisador(a), pelo contrário, reconhece-se que há produção de interferências e que essas compõem a pesquisa e a produção dos saberes.

Desse modo, implicação não se refere a uma decisão deliberada ou à vontade do(a) pesquisador(a). Na análise de implicações, avalia-se como nos relacionamos com as coisas, que efeitos nossas intervenções produzem, que lugares ocupamos nas relações e nos espaços. Uma noção de que nossas posições não são fixas e de que nossos saberes não são verdades absolutas, universais e eternas (LOURAU, 2004a).

Portanto, ao propor a análise de implicações estávamos abrindo espaço para problematizar a própria pesquisa, para pensar os caminhos que estávamos tomando.

E ao escrever o diário de campo percebemos que percursos o grupo havia trilhado. Notamos que, principalmente nos primeiros encontros, foi difícil para as pesquisadoras e os(as) participantes problematizarem os modos de pesquisar, trabalhar, ensinar e aprender; mas ao longo da pesquisa construímos coletivamente outros modos e, pouco a pouco, acompanhamos os efeitos de nossas intervenções. Assim, distanciamo-nos da ideia de uma realidade dada e de que não há nada a ser feito, fugíamos da fantasia de que deveríamos transmitir modelos e técnicas aos(às) professores(as) de como ensinar.

Foi preciso evitarmos o lugar de quem aponta os caminhos, as saídas, que traz as respostas prontas. Tarefa que não foi fácil. Algumas vezes os especialismos ${ }^{16}$ nos atravessaram.

Danilo iniciou dizendo: 'na aula passada...' ' Em forma de coro nós [pesquisadoras] e os(as) demais professores(as) dissemos: 'aula?'. E os risos surgiram. Danilo retomou e disse: 'encontro'. Primeiro, em uma conversa anterior, ele chamou o encontro de terapia e depois de aula.

Essa história de aula nos pegou, pois esse não era o objetivo do grupo, parecer uma aula, na qual as pesquisadoras ensinariam modos de ser professor(a), modos de dar aula. Pretendíamos realizar análises coletivas do trabalho com os(as) professores(as) e construir estratégias de ensino e aprendizagem.

Esse é um ponto a que precisamos estar atentas, uma tentativa de escapar aos especialismos, lugar de quem sabe e deve ensinar, onde há hierarquização dos saberes (FRAGMENTO DO DIÁRIO DE CAMPO). 
Essas foram problematizações que surgiram do próprio grupo com os(as) professores(as) e nos fizeram pensar quais os efeitos de nossas intervenções nesta pesquisa. Quando Danilo chamou o encontro do grupo de “aula”, isso nos inquietou e produziu análises sobre nossas práticas como pesquisadoras. Será que temos assumido uma postura de centralidade, de verdade? Como ocupar o lugar de especialista desmontando-o a cada momento ${ }^{17}$ ? Será que as atividades que solicitamos aos(às) professores(as) produziram essa relação? Como fazer para sustentar a conversa? Como desestabilizar as relações de poder e saber?

Mas também chama nossa atenção o fato de termos sido notados(as). Somos um grupo pequeno em quantidade, mas que, em meio à movimentação da escola, dos tarefismos, dos desafios cotidianos, fomos percebidos(as) por alguém que questiona ao Danilo sobre o que fazíamos. É bom saber que há pessoas atentas ao que se passa nessa escola. Pode parecer pouco, mas talvez seja alguém que possamos contagiar. Será que algo de nosso movimento o(a) afetou? E como o(a) afetou?

Nessas conversas, os(as) participantes também produziam torções em suas concepções de trabalho, de formação, de como ser professor(a), entre outras - não só as pesquisadoras se deslocaram. Como no fragmento a seguir, no qual Marcela contrapõe duas formas distintas de definir formação: “a formação nos dá a ilusão de estarmos prontos(as) ou o desejo de estarmos prontos(as). Mas as coisas não são assim, a gente se forma no dia a dia, com as experiências de trabalho, é pensar a formação como processo e como experienciação" (FRAGMENTO DO DIÁRIO DE CAMPO).

Essas problematizações foram surgindo nas conversas e nos diários. Fomos, pesquisadoras e participantes, dando visibilidade às formas de trabalho dos(as) professores(as) e das pesquisadoras, acompanhando os efeitos desses modos de trabalho. Paulatinamente, outros modos de pesquisar, ensinar e aprender foram construídos. No trecho a seguir, a professora Paula, por meio de uma atividade de experienciação com a escrita, após a leitura de um poema, nos contou como outras estratégias de ensino e aprendizagem emergiram.

Paula escreveu sobre Higor ${ }^{18}$ [...] um jovem de 25 anos com necessidades educacionais específicas que apresenta dificuldades na leitura e escrita, que vem aprendendo e ensinando muito. E o trabalho de Paula e dos(as) demais professores(as) com ele é bem interessante, porque eles(as) precisam romper com a ideia de valorização dos modos tradicionais de ensinar. E eles(as) perceberam que, por mais que Higor tenha dificuldades com a leitura, ele compreende os conteúdos do ensino médio e constrói os percursos de seu pensamento [...]. Isso é muito precioso. [...] A turma percebe que 
eles(as) se ajudam, um(a) aprende com o(a) outro(a), que as estratégias não são apenas para Higor, mas que todos(as) progridem com elas. Não se negam as diferenças de Higor, professores(as) e estudantes compóem com elas outros modos de ensinar e aprender que não são apenas para ele, mas para o grupo de estudantes do $1^{\circ} \mathrm{MIV}\left[1^{\circ}\right.$ ano do Ensino Médio Integrado ao Curso Técnico de Mecânica, turno vespertino] (FRAGMENTO DO DIÁRIO DE CAMPO).

Pudemos acompanhar no fragmento do diário que, diante do desafio de trabalhar com um estudante com necessidades educacionais específicas, os(as) professores(as) construíram outros modos de trabalho docente. Foi preciso alterar os modos de dar aula. Os(as) professores utilizaram mais áudio e imagens, usaram também checklist para auxiliar na resolução de problemas, produziram outras formas de avaliá-lo - era necessário que alguém lesse para ele -, entre outras. Essas estratégias não afetaram apenas Higor, mas também os(as) demais estudantes e os(as) professores(as), que foram percebendo como era importante disponibilizar outras formas de desenvolver um conteúdo, romper com as tradições.

Não conhecíamos tantos detalhes do trabalho daqueles(as) colegas professores(as) e, com a pesquisa, acompanhamos como faziam, quais eram suas inquietações, seus medos, suas dúvidas; e construímos juntos(as) outros modos de dar aula e de fazer pesquisa. Um(a) acolhendo e sendo acolhido(a) pelo(a) outro(a). Um movimento de estar lado a lado, professores(as) e pesquisadoras. Tratou-se de habitar um território onde pesquisadoras, participantes e campo de pesquisa se construíram na trajetória.

Apostamos nas fissuras, nas bifurcações que emergiram na escola. Nos modos de ser professor(a) que racharam as formas hegemônicas de trabalho. Uma atenção às singularidades.

\section{Considerações finais}

Nesta escrita, deixamos algumas pistas de como construímos o grupo da pesquisa com os(as) professores(as), espaço que fomentou a emergência, a produção e o compartilhamento de saberes situados, o que visibilizou e potencializou a criação de outros modos de ensinar, aprender e trabalhar que se diferenciam da transmissão de informações e a aquisição de habilidades.

Nosso intuito, com esse artigo, também foi mostrar que há no Ifes Campus São Mateus modos de trabalho que valorizavam a criação e que eles podem ser fortalecidos e expandidos, pois, mesmo que essa escola se configure como espaço de regulamentação 
dos modos de vida, ela também comporta fissuras nos modos hegemônicos, o que possibilita expansão da vida.

Podemos afirmar que, nessa escola, cabem outros modos de ser professor(a) e estudante. Há vidas que insistem em escapar aos controles, que resistem, que problematizam seus modos de ser docente, que se desafiam a interromper os automatismos do pensamento e questionar suas práticas, no intuito de promover fissuras, rachaduras nas naturalizações, ou seja, promover desnaturalizações.

Possivelmente, se buscássemos neutralidade, objetividade ou imparcialidade em nossos modos de pesquisar, não teríamos acompanhado os movimentos que emergiram no grupo com esses(as) professores(as): as diferenças, as problematizações, as dificuldades para ensinar, os estereótipos, os modos como eles(as) têm trabalhado, as experienciações e seus efeitos, as tradições da escola, a alegria, os conflitos e as disputas, o vínculo de confiança e o fortalecimento de práticas inventivas.

Assim, fomos compondo este texto com pistas, indícios, sinais de como essa pesquisa se constituiu, como tomou formas, sempre provisórias. Não havia um método único e prescritivo com regras já prontas e objetivos previamente estabelecidos, como se fosse possível chegar a um conhecimento único e verdadeiro (PASSOS; BARROS, 2015).

Não afirmamos, com isso, que abrimos mão do rigor da pesquisa. Não se tratou disso. Mas de não antepor o método à experiência de pesquisar. Tratou-se de uma aposta ético-estético-política de que a pesquisa se forja no ato de pesquisar, no encontro com o outro, com as leituras, com o campo, entre outros aspectos (PASSOS; BARROS, 2015).

Consequentemente, esta não foi uma escrita universal, totalizante e generalizante, pois nesta pesquisa não buscávamos encontrar um modelo de formação de professores(as) que pudesse ser aplicado a toda e qualquer escola. Não objetivávamos representar os modos de ser docente no Ifes Campus São Mateus, nem tampouco representar essa escola.

O que trouxemos foram os modos como essa experienciação de formação de professores(as), situada, foi se compondo ao nos dispormos às problematizações - um movimento de abertura ao que nos atravessava e nos tocava -, à imprevisibilidade e à descontinuidade. $\mathrm{O}$ trabalho com um outro regime de tempo valorizou as fissuras nos modos tradicionais de ser professor(a) e não a eficiência, a solução de problemas e os tarefismos. 
Assim, fomos acompanhando como esse trabalho coletivo, esse exercício de pensamento que tem uma direção comum de pensar modos de ensinar e aprender que privilegiassem a criação foi construindo ao longo dos encontros outros modos de ser professor(a). Como a fala de um(a) colega se configurava como pista para o(a) outro(a). Como as estratégias construídas não eram de Marcela, Gabriela, Paula, Danilo, Saulo ou Bernardo, mas do grupo. E elas emergiam nas análises coletivas, sem pressa, e feitas a muitas mãos.

Compreendemos que a pesquisa-intervenção e a análise micropolítica nos apontam saídas frente aos endurecimentos e cristalizações. E destacamos a potência dos pequenos grupos, da atenção aos detalhes, das conversas e experienciações como ferramentas para fissurar as tradições escolares e as formas de existência que aprisionam a vida.

\section{Referências}

ABREU, Caio Fernando. Morangos mofados. 12. ed. Rio de Janeiro: Nova Fronteira, 2015. p. 214-223.

ALVAREZ, Johnny; PASSOS, Eduardo. Cartografar é habitar um território existencial. In: PASSOS, Eduardo; KASTRUP, Virgínia; ESCÓSSIA, Liliana da (Orgs.). Pistas do método da cartografia: pesquisa-intervenção e produção de subjetividade. Porto Alegre: Sulina, 2015. p. 131-149.

BARROS, Laura Pozzana de; KASTRUP, Virgínia. Cartografar é acompanhar processos. In: PASSOS, Eduardo; KASTRUP, Virgínia; ESCÓSSIA, Liliana da (Orgs.). Pistas do método da cartografia: pesquisa-intervenção e produção de subjetividade. Porto Alegre: Sulina, 2015. p. 52-75.

BARROS, Regina Benevides de. Grupo: a afirmação do simulacro. Porto Alegre: Sulina, 2007.

BRASIL. Lei $\mathrm{n}^{\mathrm{o}} 11.741$, de 16 de julho de 2008. Altera dispositivos da Lei no 9.394, de 20 de dezembro de 1996, que estabelece as diretrizes e bases da educação nacional, para redimensionar, institucionalizar e integrar as ações da educação profissional técnica de nível médio, da educação de jovens e adultos e da educação profissional e tecnológica. Diário Oficial [da] República Federativa do Brasil. Brasília, DF, p. 5, 17 jul., 2008. Seção 1, https://pesquisa.in.gov.br/imprensa/jsp/visualiza/index.jsp?data=17/07/2008\&jor nal $=1 \&$ pagina $=5 \&$ totalArquivos=80, acessado em 11 agosto 2020.

COIMBRA, Cecília; LEITÃO, Maria Beatriz Sá. Das essências às multiplicidades: especialismo psi e produções de subjetividades. Psicologia \& Sociedade, v. 15, n. 2, p. 6-17; jul./dez. 2003, http://www.scielo.br/pdf/psoc/v15n2/a02v15n2.pdf, acessado em 15 março de 2018. 
DELEUZE, Gilles. Diferença e repetição. Trad. Luiz Orlandi e Roberto Machado. 2. ed. rev. e atual. São Paulo: Graal, 2006.

DELEUZE, Gilles; GUATTARI, Félix. O que é filosofia? Trad. Bento Prado Jr. e Alberto Alonso Munõz. São Paulo: Ed. 34, 1993.

FOUCAULT, Michel. Ética, sexualidade, política. Org. de Manoel Barros da Moita. Trad. Elisa Monteiro e Inês Autran Dourado Barbosa. 2. ed. Rio de Janeiro: Forense universitária, 2006.

GUATTARI, Félix; ROLNIK, Suely. Micropolítica: cartografias do desejo. 12. ed. Petrópolis: Vozes, 2013.

HECKERT, Ana Lúcia Coelho; ROCHA, Marisa Lopes da. A maquinaria escolar e os processos de regulamentação da vida. Psicologia \& Sociedade, 24 (n.spe.), p. 8593, 2012, http://www.scielo.br/pdf/psoc/v24nspe/13.pdf, acessado em 26 de março de 2018.

KASTRUP, Virgínia. Aprendizagem, arte e invenção. Psicologia em Estudo, Maringá, v. 6, n. 1, p. 17-27, jan./jun. 2001, http://www.scielo.br/pdf/pe/v6n1/v6n1a03.pdf, acessado em 2 de abril de 2018.

KASTRUP, Virgínia. O funcionamento da atenção no trabalho do cartógrafo. In: PASSOS, Eduardo; KASTRUP, Virgínia; ESCÓSSIA, Liliana da (Orgs.). Pistas do método da cartografia: pesquisa-intervenção e produção de subjetividade. Porto Alegre: Sulina, 2015. p. 32-51.

KASTRUP, Virgínia. Políticas cognitivas na formação do professor e o problema do devir-mestre. Educação \& sociedade, Campinas, v. 26, n. 93, p. 1273-1288, set./dez. 2005, http://www.scielo.br/pdf/es/v26n93/27279.pdf, acessado em 2 de abril de 2018.

LAZZAROTTO, Gislei Domingas Romanzini. Experimentar. In: FONSECA, Tania Mara Galli; NASCIMENTO, Maria Lívia do; MARASCHIN, Cleci (Orgs.). Pesquisar na diferença: um abecedário. Porto Alegre: Sulina, p. 99-101, 2012, http://vocabpol.cristinaribas.org/wp-content/uploads/2016/08/Pesquisar-na-

Diferenca_Um-abeceda\%CC\%81rio.pdf, acessado em 2 de maio de 2017.

LISPECTOR, Clarice. Carência do poder criador. In: A descoberta do mundo: crônicas. Rio de Janeiro: Rocco, 1984a. p. 450.

LISPECTOR, Clarice. Sensibilidade inteligente. In: $A$ descoberta do mundo: crônicas. Rio de Janeiro: Rocco, 1984b. p. 148-149.

LOURAU, René. El diario de investigación: materiales para una teoría de la implicación. Traducido del francés por Emmanuel Carballo Villaseñor. Editorial: Universidad de Guadalajara, 1989, https://pt.scribd.com/doc/278794292/Lourau-El-diario-deinvestigacion-Materiales-para-una-teoria-de-la-implicacion-pdf, acessado em 2 de outubro de 2018.

LOURAU, René. Implicação e sobreimplicação. In: ALTOÉ, Sônia (Org.). René Lourau: analista institucional em tempo integral. São Paulo: Hucitec, 2004a. p. 186-198.

LOURAU, René. O instituinte contra o instituído. In: ALTOÉ, Sônia (Org.). René Lourau: analista institucional em tempo integral. São Paulo: Hucitec, 2004b. p. 47-65. 
OLIVEIRA, Flávia Reis de. A escrita como técnica de si: formação de professores e os modos de subjetivação. Dissertação de Mestrado. Universidade de Caxias do Sul, Programa de Pós-Graduação em Educação, Linha de Pesquisa: História e Filosofia da Educação, Caxias do Sul, 2013, https://repositorio.ucs.br/xmlui/bitstream/handle/11338/649/Dissertacao\%20Flav ia\%20Reis\%20de\%20Oliveira.pdf?sequence=1\&isAllowed=y, acessado em 26 de março de 2018.

PACHECO, CLARICE. Poesia por acaso, 2017, https://www.escritas.org/pt/n/t/1015/poesia-por-acaso, acessado 17 de maio de 2017.

PASSOS, Eduardo; BARROS, Regina Benevides de. A cartografia como método de pesquisa-intervenção. In: PASSOS, Eduardo; KASTRUP, Virgínia; ESCÓSSIA, Liliana da (Orgs.). Pistas do método da cartografia: pesquisa-intervenção e produção de subjetividade. Porto Alegre: Sulina, 2015. p. 17-31.

ROCHA, Marisa Lopes da; AGUIAR, Katia Faria de. Pesquisa-intervenção e a produção de novas análises. Psicologia ciência e profissão, Brasília, v. 23, n. 4, p. 64-73, dez. 2003, https://www.scielo.br/pdf/pcp/v23n4/v23n4a10.pdf, acessado em 14 de julho de 2020.

SADE, Christian; FERRAZ, Gustavo Cruz; ROCHA, Jerusa Machado. O ethos da confiança na pesquisa cartográfica: experiência compartilhada e aumento da potência de agir. Fractal: Revista de psicologia, Rio de Janeiro, v. 25, n. 2, p. 281 298, maio/ago. 2013, http://www.scielo.br/pdf/fractal/v25n2/05.pdf, acessado em 29 de maio de 2018.

SANTOS, Daniele Vasco; DIAS, Rosimeri de Oliveira. Invenção e formação de professores entre escritas e problematizações. In: LEMOS, Flávia Cristina Silveira; GALINDO, Dolores; BICALHO, Pedro Paulo Gastalho de; OLIVEIRA, Flávio Valentim de; SANTOS, Igor do Carmo; SANTOS, Arthur; ELMESCANY, Érica de Nazaré Marçal; ALMEIDA, Mário Tito Barros (Orgs.). Criações transversais com Gilles Deleuze: artes, saberes e política. Curitiba: CRV, 2016. p. 313-332.

SELLI, Maribel Susane. Formação docente: uma experimentação que produz ecos. In: Seminário internacional de educação, 15, 2010, Cachoeira do Sul. Anais SIEduca 2010 , http://www.sieduca.com.br/2010/index4354.html?principal=lista_trabalhos\&eix $\mathrm{o}=5 \&$ modalidade $=1$, acessado em 19 de setembro de 2017 .

STENGERS, Isabelle. Quem tem medo da ciência? São Paulo: Siciliano, 1990.

Alini Altoé

Mestre pelo Programa de Pós-Graduação em Psicologia Institucional

Universidade Federal do Espírito Santo

Psicóloga no Instituto Federal do Espírito Santo - Campus São Mateus

Email: alinialtoe@ hotmail.com

Prof. ${ }^{a}$ Dr. ${ }^{a}$ Cristiana Mara Bonaldi

Departamento de Psicologia do Polo Universitário de Rio das Ostras 


\section{Universidade Federal Fluminense \\ Programa de Pós-Graduação em Psicologia Institucional \\ Universidade Federal do Espírito Santo \\ Email: crisbonaldi@ hotmail.com}

${ }^{1}$ Pesquisa desenvolvida ao longo do Mestrado em Psicologia Institucional, na Universidade Federal do Espírito Santo.

${ }^{2}$ Faremos a opção de utilizar na escrita deste texto os gêneros masculino e feminino a fim de desconstruir a ideia de masculino como universal e de demarcar a importância das mulheres na produção de conhecimentos.

${ }^{3}$ Estamos trabalhando neste texto com a noção de produção de subjetividade desenvolvida por Deleuze e Guattari. Assim, estamos nos referindo aos modos de relação que o homem estabelece com o mundo e consigo mesmo como uma produção, fabricação e modelação. Há dois processos em voga na produção de subjetividade: individuação e singularização ou subjetivação. A política de individuação da subjetividade produz sujeitos serializados, modelados segundo a ordem vigente, universaliza os modos de organização da vida, individualiza os sujeitos. Já a singularização abre possibilidades para criação de outras existências, rompe com os modos corriqueiros de vida.

${ }^{4}$ Lourau (2004b: 47) o define como "[...] a ordem estabelecida, os valores, modos de representação e de organização considerados normais, como igualmente os procedimentos habituais de previsão (econômica, social e política)".

5 Aquelas que contestam, desestabilizam, deslocam o instituído. Instituído e instituinte não se encontram apartados, ora estão juntos, ora separados. Assim como os movimentos instituintes se desdobram em movimentos criadores e estremecem os modos de existência, o instituído procura incorporar esses novos modos de vida.

${ }^{6}$ Nome fictício.

${ }^{7}$ Nome fictício.

${ }^{8}$ Nome fictício.

${ }^{9}$ Nome fictício.

${ }^{10}$ Nome fictício.

${ }^{11}$ Remete a uma política cognitiva de invenção, na qual o foco não é a solução de problemas, mas a invenção de problemas, a experiência de problematização (DELEUZE, 2006). “[...] A invenção é sempre invenção do novo, sendo dotada de uma imprevisibilidade que impede sua investigação e o tratamento no interior de um quadro de leis e princípios invariantes da cognição [...]” (KASTRUP, 2005: 1274).

12 Nome fictício.

13 A Lei $N^{\circ}$ 11.741, de 16 de Julho de 2008, define que o ensino médio integrado articula a educação propedêutica à educação profissional do ensino médio em um único currículo escolar. Ao finalizar o curso, o estudante terá habilitação técnica na área do curso que realizou e também possibilitará o prosseguimento dos estudos na educação superior (BRASIL, 2008). Na escola, percebemos que essa modalidade de ensino evidencia algumas dualidades instituídas entre ensino técnico e médio, entre formação profissional e intelectual, entre estudantes que ingressarão no mercado de trabalho e na universidade. Essas oposições geram hierarquização dos saberes e também dos(as) professores(as).

${ }^{14}$ São forças que nos atravessam e nos constituem. Falamos de afectos, pois eles transbordam os sentimentos e as afecções são independentes de um sujeito que sente, assim como os perceptos transbordam as percepções ordinárias, uma vez que não dependem de um sujeito que os experimenta. Trata-se de algo que não sabemos ao certo o que é, mas que faz nossos corpos vibrarem e seguirem em uma certa direção (DELEUZE; GUATTARI, 1993).

15 Aplicativo multiplataforma de mensagens instantâneas e chamadas de voz para smartphones, no qual os(as) usuários(as) podem enviar mensagens de texto, imagens, vídeos, documentos em PDF e fazer ligações por meio de uma conexão com a internet. 
16 “[...] identificado como o lugar da competência, do conhecimento/reconhecimento, da verdade, dos modelos, da autoridade, do discernimento, da legitimidade e adequação de certos modos de ser [...]" (COIMBRA; LEITÃO, 2003: 8).

${ }^{17}$ Uma referência a Barros (2007: 226), que afirma que temos o desafio de "[...] ocupar o lugar do especialista, desmontando-o a cada momento".

18 Nome fictício. 